\title{
ATIVOS INTANGÍVEIS E O DESEMPENHO ECONÔMICO-FINANCEIRO: COMPARAÇÃO ENTRE OS PORTFOLIOS DE EMPRESAS TANGÍVEL-INTENSIVAS E INTANGÍVEL-INTENSIVAS
}

\author{
THE ROLE OF PEOPLE MANAGEMENT IN THE \\ INSERTION AND MAINTENANCE OF DISABLED PERSONS \\ ORGANIZATIONS IN THE LIGHT OF FILM ANALYSIS
}

Recebido: 16-04-2014 Aceito: 02-04-2015

Marta Olivia Rovedder de Oliveira ${ }^{1}$ Douglas Pinheiro Schossler ${ }^{2}$ Rogério Estrela Campos ${ }^{3}$ Fernando Bins Luce ${ }^{4}$

\section{RESUMO}

Os ativos intangíveis são capazes de produzir benefícios futuros, que constituem importantes fatores de diferenciação, contribuindo para a obtenção de vantagens competitivas relevantes (CARMELI; TISHLER, 2004; PEREZ; FAMÁ, 2006a). Entretanto, as abordagens tradicionais de avaliação financeira apresentam dificuldade em avaliar e valorizar negócios com ativos intangíveis significantes (LEV, 2001; MIZIK; JACOBSON, 2008; MIZIK; JACOBSON, 2009). Assim, neste trabalho, buscou-se comparar o desempenho (via indicadores contábil-financeiros, durante cinco anos) de dois portfólios: um composto pelas empresas com elevada proporção de intangibilidade e o outro relativo às empresas que possuem pequena proporção de intangibilidade, com o intuito de contribuir com a literatura sobre o tema ao gerar conhecimento acerca do mercado brasileiro. Os resultados encontrados demonstram que o portfólio de empresas com maior proporção de intangibilidade apresenta desempenho superior na grande maioria dos períodos e indicadores avaliados. Tal resultado constitui mais uma evidência de que os ativos intangíveis são capazes de gerar vantagem competitiva para as suas respectivas companhias, inclusive no cenário brasileiro.

Palavras-chave: ativos intangíveis, retorno de investimentos, mercado financeiro brasileiro, valor de mercado.

\footnotetext{
1 Possui graduação em Administração pela Universidade Federal de Santa Maria - UFSM. Mestrado e doutorado em Administração pela Universidade Federal do Rio Grande do Sul - UFRGS. Atualmente é professora na Universidade Federal de Santa Maria - UFSM. Santa Maria, Rio Grande do Sul, Brasil. E-mail: mrovedder@gmail.com

2 Possui graduação em Administração pela Universidade Federal do Rio Grande do Sul - UFRGS. Porto Alegre, Rio Grande do Sul. Brasil. E-mail: douglas.psch@hotmail.com

3 Possui graduação em Administrção pela Universidade Federal do Rio Grande do Sul - UFRGS. Porto Alegre, Rio Grande do Sul. Brasil. E-mail: rcecampos@gmail.com

4 Possui graduação em Administração pela Universidade Federal do Rio Grande do Sul - UFRGS. Mestrado e doutorado em Administração pela Michigan State University - MSU. Atualmente é professor da Universidade Federal do Rio Grande do Sul - UFRGS. Porto Alegre, Rio Grande do Sul. Brasil. E-mail: fernando.luce@ufrgs.br
} 


\section{ABSTRACT}

The intangible assets are able to produce future benefits that are important differentiating factors contributing to the achievement of important competitive advantages (CARMELI; TISHLER, 2004; PEREZ; FAMÁ, 2006a). However, traditional approaches to financial evaluation have difficulty in assessing and valuing business with significant intangible assets (LEV, 2001; MIZIK; JACOBSON, 2008; MIZIK; JACOBSON, 2009). Hence, this study sought to compare (by accountancy and financial indexes, during 5 years) the performance of two portfolios: firms with a high proportion of intangibility and one of possessing a small proportion of intangibility, in order to contribute to the literature and generate knowledge about the Brazilian market. The results show a superior performance of the intangible assets portfolio during the most of periods and indexes. It is further evidence that intangible assets are capable of generating competitive advantage for their respective companies, including in the Brazilian scenario.

Keywords: intangible assets, investment returns, the Brazilian financial market, market value.

\section{INTRODUÇÃO}

Uma importante questão estratégico-competitiva é o motivo pelo qual o desempenho financeiro operacional e estratégico difere nas empresas (VILLALONGA, 2004). Uma possível e abrangente explicação para esse questionamento consiste nos recursos que as próprias empresas possuem. Dentre esses recursos, a teoria da Visão Baseada em Recursos (Resource Based View - RBV) "aponta para os recursos intangíveis como os principais motores da sustentabilidade das diferenças de desempenho entre as empresas" (VILLALONGA, 2004, p. 2006). Ativos intangíveis chegam a ser considerados os ativos mais importantes de várias das maiores e mais poderosas companhias do mundo (LIN; TANG, 2009), dado que uma proporção significativa do valor de mercado de uma empresa reside nos ativos intangíveis não presentes no Balanço Patrimonial (LUSCH; HARVEY, 1984; SRIVASTAVA; SHERVANI; FAHEY, 1998; AAKER; JACOBSON, 2001). Os ativos intangíveis são capazes de produzir benefícios futuros e constituem importantes fatores de diferenciação, contribuindo para a obtenção de vantagens competitivas relevantes (FÁMA, 2006) e para a melhoria do desempenho das organizações (BARNEY, 1991; DELIOS; BEAMISH, 2002).

Boa parte dos investimentos em ativos intangíveis está intimamente relacionada com investimentos em marketing, como construção da marca, por exemplo (MIZIK; JACOBSON, 2009). Além do valor da marca, existem outros ativos atinentes à área de marketing ou ativos baseados no mercado, tais como clientes (customer equity), relacionamentos e canais (BRODIE; GLYNN; VAN DURME, 2002; REGO; OLIVEIRA; LUCE, 2008).

Salienta-se, contudo, que as abordagens tradicionais de avaliação financeira apresentam dificuldade em avaliar negócios com ativos intangíveis significantes (LEV, 2001; MIZIK; JACOBSON, 2008; MIZIK; JACOBSON, 2009) e que os benefícios dos ativos da área de marketing não são corretamente descritos na avaliação contábil das empresas (SRIVASTAVA; SHERVANI; FAHEY, 1998; MIZIK; JACOBSON, 2008). A grande maioria dos ativos intangíveis sequer é registrada ou contabilizada nos demonstrativos financeiros das organizações. Isso acontece, principalmente, devido à grande dificuldade de identificação, definição e mensuração desses ativos por parte das empresas (PEREZ; FAMÁ, 2006a). Pode-se afirmar, assim, que "os intangíveis representam um desafio especial para os analistas, devido às informações complexas que contêm" (HIGGINS, 2013, p. 155). Além disso, é complexo verificar o resultado desse investimento, tendo em vista que, frequentemente, ele ocorre apenas em longo prazo (LEV, 2001; UPTON, 2001; AMBLER, 2003). Dessa forma, muitas vezes, investimentos realizados em ativos da área de marketing, como em marcas e relacionamento com os clientes, assim como em outros ativos intangíveis das empresas, são considerados custos e não investimentos. 
Nesse sentido, existe a necessidade de pesquisas que melhor compreendam como os recursos de marketing exercem influência no desempenho empresarial, conforme destacou o Marketing Science Institute (MSI) - instituto fundado em 1961, que visa aliar os estudos da teoria de Marketing com a prática das empresas - em uma de suas prioridades de pesquisa para o triênio de 2012 a 2014. Tal instituto também apontou, dentre as prioridades de pesquisa para o período de 2010 a 2012, o intento de compreender e mensurar os resultados das empresas provenientes de investimentos em marketing. Portanto, um dos pilares deste trabalho é ir ao encontro dessas prioridades de pesquisa, ao buscar uma verificação empírica da importância dos ativos intangíveis, visando auxiliar na tomada de decisão dos administradores em relação a investimentos em ativos intangíveis.

Teoricamente, crê-se que a presença de recursos intangíveis auxilia a criar e manter um desempenho superior para a empresa, já que dificulta que ela seja imitada ou substituída. No entanto, fazse necessário averiguar, empiricamente, essa crença. Para avaliar os ativos intangíveis, os argumentos da RBV parecem sugerir um teste acerca da importância dos intangíveis em relação aos bens tangíveis, ou seja, averiguar o Grau de Intangibilidade (GI) dos recursos de uma empresa (VILLALONGA, 2004).

Nesse sentido, o objetivo geral da presente pesquisa é diagnosticar se há diferença entre o desempenho econômico de dois portfólios de empresas presentes no mercado acionário brasileiro: a) um portfólio de empresas classificadas como de grande proporção de intangibilidade; e b) um portfólio de empresas classificadas como de pequena proporção de intangibilidade. Dentre os objetivos específicos, este estudo busca estimar o nível médio de intangibilidade das empresas brasileiras de capital aberto, com ações cotadas na Bolsa de Valores de São Paulo (BOVESPA), visando classificá-las dentre os portfólios supracitados, bem como aferir os índices de rentabilidade - retorno sobre o investimento, margem operacional, margem líquida, índice de liquidez e liquidez corrente - e uma medida de desempenho de mercado - beta (risco) - dos portfólios formados. Para a realização do estudo, foram elaboradas as seguintes hipóteses:

a) Hipótese Fundamental Nula (HO) - não existe diferença entre o desempenho econômico de um portfólio de empresas de grande proporção de intangibilidade e um portfólio de empresas de pequena proporção de intangibilidade;

b) Hipótese Alternativa ( $\mathrm{H} 1)$ - há diferença entre os dois portfólios.

Cabe salientar que, de acordo com a análise realizada, ainda existem poucos estudos acerca desse tema que abordem, especificamente, o mercado acionário brasileiro (HONORATO, 2008; KAYO, 2002; OLIVEIRA, 2009). Assim, o presente trabalho busca preencher esse gap. Além disso, torna-se ainda mais importante estudar os ativos intangíveis das companhias brasileiras em um momento de mudança da legislação nacional com relação às Sociedades Anônimas (S.As), a qual incluiu questões sobre o registro contábil dos ativos intangíveis.

Para isso, o presente artigo apresenta uma revisão bibliográfica sobre ativos intangíveis no capítulo dois; o método, no capítulo três, com a descrição da composição da amostra, das variáveis utilizadas e dos procedimentos para a análise dos dados; a análise dos resultados, no capítulo quatro; e as considerações finais, no capítulo cinco, com sugestões para futuras pesquisas.

\section{REFERENCIAL TEÓRICO}

\subsection{Ativos intangíveis}

Segundo Barney (1991), um ativo pode ser definido como qualquer atributo físico, organizacional ou humano que permita que uma firma gere e implemente estratégias que melhorem a sua eficiência e eficácia no mercado, desempenhando um importante papel na criação de valores 
da empresa (CARMELI, 2001). Por sua vez, Perez e Famá (2006) os descrevem como todo recurso físico ou não - que esteja sob o controle de uma organização e que possa ser utilizado para produzir produtos ou serviços aos seus clientes, visando à geração de benefícios econômicos futuros. Os ativos podem ser tangíveis, intangíveis, internos, externos, presentes ou não no balanço da empresa.

A teoria da Visão Baseada em Recursos (Resource Based View - RBV) sinaliza a importância dos ativos intangíveis para o desempenho e a sustentação da vantagem competitiva das empresas (BARNEY, 1991; VILLALONGA, 2004). Enquanto os principais recursos tangíveis são mais facilmente alterados, bem como imitados, os recursos intangíveis mais significativos são muito difíceis de mudar e quase inimitáveis (CARMELI, 2001).

Os ativos intangíveis, segundo Upton (2001), são recursos não físicos, geradores de prováveis benefícios econômicos futuros para uma entidade, que foram adquiridos por meio de troca ou, ainda, desenvolvidos internamente, baseados em custos identificáveis, que têm vida limitada, possuem valor de mercado próprio e pertencem à entidade ou são controlados por ela. Kayo (2002) complementa essa ideia, mencionando que os ativos intangíveis são o conjunto estruturado de conhecimentos, práticas e atitudes da empresa que, interagindo com seus ativos tangíveis, contribui para a formação do valor das empresas. Os ativos intangíveis podem ser classificados em quatro grupos: humanos, de inovação, estruturais e de relacionamento (KAYO, 2002). A Tabela 1, exposta a seguir, traz exemplos de cada um deles.

Tabela 1 - Tipos de Ativos Intangíveis

\begin{tabular}{l|l}
\hline Humanos & Inovação \\
- Conhecimento, talento, capacidade, experiên- & - Pesquisa e desenvolvimento \\
cia e habilidade dos empregados & - Patentes \\
- Administração superior ou empregados-chave & - Fórmulas secretas \\
- Treinamento e desenvolvimento & - Know-how tecnológico \\
& - Direitos de exploração e operação \\
Estruturais & Relacionamento \\
- Processos & - Marcas \\
- Softwares proprietários & - Logos \\
- Bancos de dados & - Trademarks \\
- Sistemas de Informação & - Costumer loyalty \\
- Sistemas administrativos & - Goodwill \\
- Inteligência de mercado & - Direitos autorais \\
- Canais de mercado & - Contratos com distribuidores, varejistas, atacadistas e \\
& parceiros estratégicos \\
& - Contratos de licenciamento e franquias \\
& - Contratos de execução, cotas de produção e acordos \\
de não competição
\end{tabular}

Fonte: Adaptado de Kayo (2002)

Para Perez e Fáma (2006a), os ativos intangíveis são importantes fatores de diferenciação e contribuem muito para a obtenção de relevantes vantagens competitivas. Isso se deve à característica fundamental de todo ativo intangível: sua singularidade. Os ativos intangíveis constituem elementos sem propriedade física, mas possuem valor agregado e que podem ser comercializados por uma organização (MANTOVANI; SANTOS, 2014). Logo, não se pode definir o ativo intangível apenas como aquele que não possui existência física ou que não pode ser tocado - tal definição é simplista e incompleta, incluindo, erroneamente, outros ativos, como créditos fiscais e despesas pagas antecipadamente. De acordo com Barney (1991), os ativos intangíveis são únicos, sendo considerados recursos valiosos, raros, inimitáveis e insubstituíveis, que podem criar valor para a firma (SRIVASTAVA et al., 1998). 
Conforme o International Accounting Standards Committee Foundation (IASC, 2008), em sua resolução 38.12, um ativo intangível deve ser capaz de ser separado da entidade ou dividido e vendido, transferido, licenciado, alugado ou trocado, seja individualmente, seja em conjunto com um contrato ativo ou passivo relacionado. Pode também, segundo essa fundação, ser resultado de direitos contratuais ou de outros direitos legais, quer esses direitos sejam transferíveis, quer sejam separáveis da entidade ou de outros direitos e obrigações. Além de possuírem tais características, é esperado que os futuros benefícios econômicos advindos dos ativos intangíveis sejam canalizados para a organização e que seu custo possa ser fielmente mensurado (IASC Foundation, 2008).

Entretanto, existe uma grande dificuldade na identificação e na definição desses ativos, na mensuração de seus valores e na estimação de suas vidas úteis (PEREZ; FAMÁ, 2006a). As abordagens tradicionais de avaliação financeira apresentam dificuldade em avaliar negócios com ativos intangíveis significantes (LEV, 2001; MIZIK; JACOBSON, 2008; MIZIK; JACOBSON, 2009). Frequentemente, empresas possuem ativos intangíveis cujos benefícios não são corretamente descritos na sua avaliação contábil (SRIVASTAVA; SHERVANI; FAHEY, 1998; MIZIK; JACOBSON, 2008), pois, normalmente, as demonstrações contábeis existentes reconhecem esses ativos somente quando adquiridos. Assim sendo, deveriam ser desenvolvidas as bases para o reconhecimento e a mensuração de ativos intangíveis (UPTON, 2001).

Tal avaliação se faz extremamente pertinente, dado que uma proporção significativa do valor de mercado de uma empresa reside, atualmente, mais nos ativos intangíveis não presentes no balanço do que nos demais ativos (LUSCH; HARVEY, 1994). Outros autores, como Fisher (2007) e Barth e Clinch (1998), ressaltam a relevância da valoração desses ativos, como comprovado em estudos acerca do mercado de capitais que apontam que analistas preferem negociar com companhias que disponham de ativos intangíveis importantes.

Um dos problemas verificados na mensuração dos intangíveis é a diferença de tratamento e de normativas encontrada em diferentes países, faltando uma linguagem contábil comum. No Brasil, em 28 de dezembro de 2007, foi sancionada a Lei n. 11.638/07, que modificou a Lei das S.As, tendo como objetivo "a atualização da legislação societária brasileira para possibilitar a convergência das práticas contábeis adotadas no Brasil com aquelas constantes nas normas internacionais de contabilidade" (HONORATO, 2008, p. 30). Essa lei apontou o "intangível" como um novo subgrupo de contas, incluindo o ágio, para a apresentação no balanço patrimonial. 0 Pronunciamento Técnico CPC-04, de 25 de abril de 2008, do Comitê e da Comissão de Valores Mobiliários (CVM), acerca do tratamento contábil dos ativos intangíveis, fundamentou-se no pronunciamento sobre ativos intangíveis que foi emitido pelo International Accounting Standards Board (IASB) (IAS 38 - Intangible Assets) (HONORATO, 2008).

A IASC Foundation (2008) faz uma distinção entre as regras relativas ao reconhecimento e à mensuração dos ativos intangíveis, de acordo com o modo como eles são adquiridos. As formas de aquisição são as seguintes: adquiridos separadamente, adquiridos como parte de uma combinação de negócios, adquiridos por meio de subsídio do governo, adquiridos por meio de uma troca de ativos e gerados internamente. Independentemente da forma de classificação dos ativos intangíveis e de como é feita a sua mensuração, eles têm sido considerados importantes para as empresas, conforme apresenta o capítulo 2.2 .

\subsection{Importância do ativo intangível}

Por que tentar valorar o ativo intangível? Segundo Kayo (2006), valorar os ativos intangíveis é importante por vários motivos. Eles servem como base para operações de fusão e aqui- 
sição e também para operações de securitização ou garantias de empréstimo (REILLY; SCHWELLS, 1998). Ademais, conhecer seu valor facilita, consequentemente, sua gestão. Ambler (2003) salienta que as estratégias de uma empresa devem levar em consideração a mensuração para indicar o progresso que a firma está procurando. Segundo o mesmo autor, os ativos intangíveis conferem segurança para lucros futuros.

Além disso, o ativo intangível gera vantagens competitivas (CARMELI; TISHLER, 2004) e é um meio de as empresas diferenciarem-se dos seus competidores (STEWART, 2001). $O$ ativo intangível não somente é relevante para obter vantagens competitivas, mas também para manter essa competitividade (KAYO, 2002).

Um dos ativos intangíveis que tem maior visibilidade é a marca. Pesquisas mostram uma forte associação entre o valor das marcas e o valor de mercado das empresas proprietárias dessas marcas. Em conformidade com Oliveira (2009), as marcas mais valiosas são compostas, em geral, por empresas possuidoras de alto valor de mercado. Uma marca forte proporciona maior lealdade, menor vulnerabilidade às ações de marketing da concorrência, menor vulnerabilidade às crises de marketing, maior margem de lucros, maior inelasticidade a aumentos de preço, maior elasticidade a reduções de preço, possíveis oportunidades de licenciamento ou extensão da marca e lucros operacionais maiores e mais consistentes ao longo do tempo (KELLER, 1998).

Um exemplo dessa importância pode ser encontrado no relatório anual da Brand Finance das 500 marcas mais valiosas do mundo (2008). Tomando como exemplo a Wal-Mart e a CocaCola, as mais valiosas do ranking, os ativos intangíveis compõem, respectivamente, $68 \%$ e $88,9 \%$ do valor total da empresa. Observe-se, nesse sentido, que a divisão do total dos ativos intangíveis foi realizada de acordo com a IASC Foundation (2008).

Vários autores mencionam que os ativos intangíveis oriundos da área de marketing - tais como valor da marca, valor do cliente, relacionamento, dentre outros - são elementos críticos de valor da empresa (AKSOY et al., 2008; AAKER; JACOBSON, 2001; CHIABI; GONÇALVES, 2010; SRIVASTAVA; SHERVANI; FAHEY, 1998; RUST et al., 2004; VILLANUEVA; YOO; HANSSENS, 2008). Contudo, tais ativos nem sempre são contabilizados nos relatórios contábeis e financeiros da empresa, desvalorizando as ações de marketing e os seus respectivos efeitos no valor das empresas.

Os profissionais de marketing têm proposto, recentemente, que grande parte do problema com a previsão do desempenho da empresa diz respeito, nos modelos normalmente utilizados pelos analistas, à não inclusão dos intangíveis e das métricas não financeiras relativas à base dos clientes (GUPTA; LEHMANN; STUART, 2004; AKSOY et al., 2008). Ao mesmo tempo em que as áreas de finanças e contabilidade raramente captam os ativos intangíveis baseados no mercado (LEHMANN, 2004), a área de marketing está sendo desafiada a avaliar o valor criado por suas ações para a empresa e a comunicar-se com as áreas financeira e contábil, criando a necessidade de traduzir os desempenhos dos esforços da área em termos financeiros (RUST et al., 2004; SRINIVASAN; HANSSENS, 2009).

Argumenta-se que a influência do marketing, tanto como uma disciplina quanto como uma função na empresa, tem diminuído devido à falta de relações conceituais e de linguajar que permita à área se engajar em um significativo diálogo com a área de finanças e com a alta administração (RUST et al., 2004; SRIVASTAVA; SHERVANI; FAHEY, 1998; SRIVASTAVA; SHERVANI; FAHEY, 1999). Dessa forma, a demonstração da relevância dos ativos intangíveis, oriundos em grade parte das ações da área de marketing, pode permitir tecer a relação desta área com o desempenho econômico-financeiro via utilização de terminologia e indicadores contábil-financeiros. 


\section{MÉTODO}

O presente estudo caracteriza-se como descritivo, pois visa comparar o desempenho econômico de dois diferentes portfólios classificados com base na intangibilidade das empresas. Dessa forma, esta pesquisa apresenta uma abordagem quantitativa. As principais etapas para a realização deste estudo foram a coleta de dados secundários, o tratamento dos dados, a composição dos portfólios, os cálculos das medidas e variáveis (Grau de Intangibilidade - GI - e desempenho econômico) e a comparação dos resultados dos portfólios, conforme mostra a Figura 1. O presente trabalho tem como inspiração o método adotado por Kayo e Famá (2004).

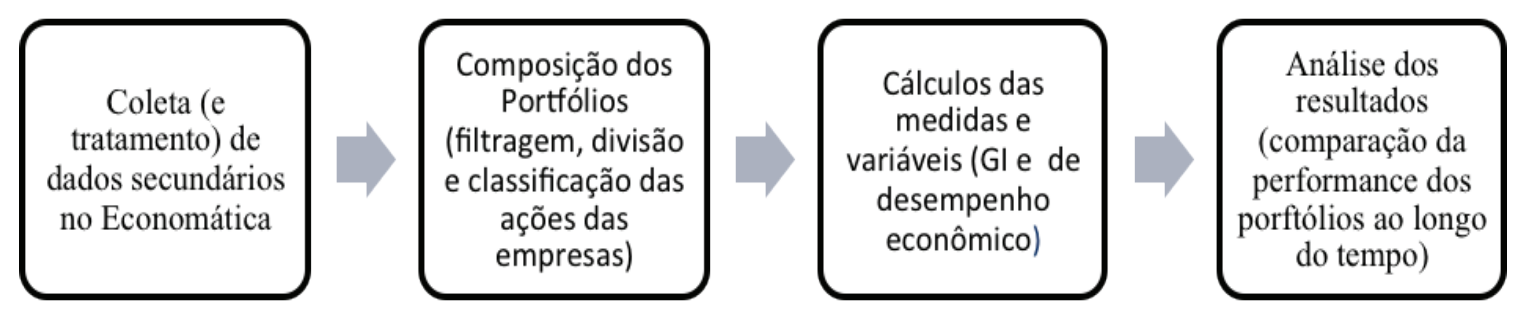

Figura 1 - Esquematização das etapas da pesquisa

Com base no objetivo proposto, optou-se por coletar dados das empresas brasileiras participantes da Bolsa de Valores de São Paulo (BOVESPA), com auxílio do software Economática*. Em seguida, esses dados foram transportados para uma planilha eletrônica do Microsoft Excel ${ }^{\circ}$, com o intuito de realizar os cálculos das variáveis. Por fim, utilizou-se o programa Statistical Package for the Social Sciences ${ }^{\circ}$ (SPSS) para a análise estatística das variáveis.

A seguir, a composição dos portfólios, as variáveis utilizadas e os procedimentos para a análise dos dados desta pesquisa são apresentados.

\subsection{Composição dos portfólios}

Para a composição dos portfolios, foram realizadas quatro etapas, as quais são apresentadas na Figura 2 e são detalhadas na sequência. 


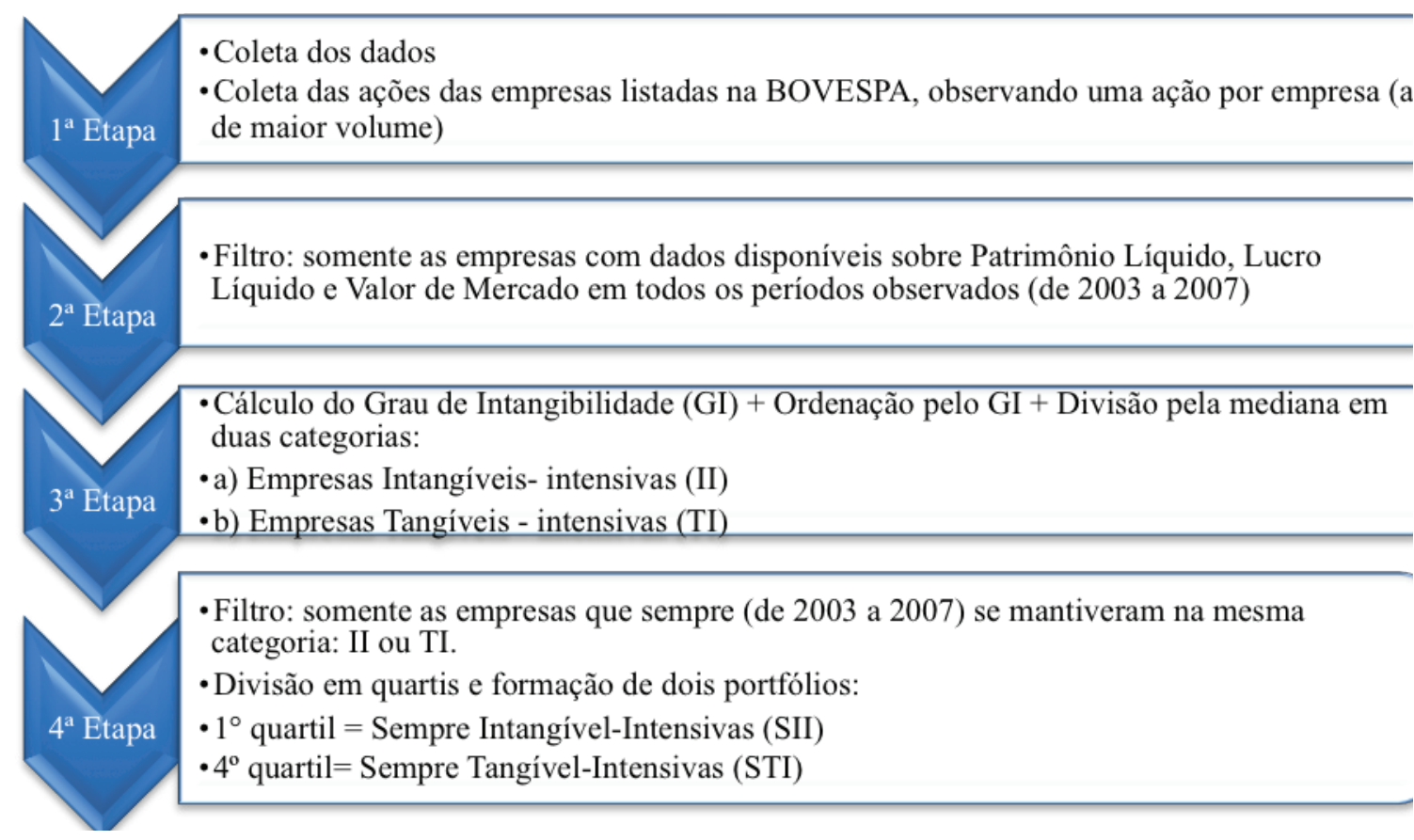

Figura 2 - Composição dos portfólios

Primeiramente, foram coletados dados somente das empresas brasileiras com ações listadas na BOVESPA, observando uma ação por empresa (a de maior volume), segundo os dados disponíveis no Economática.

Na segunda etapa, foram removidas da amostra as empresas que não apresentavam dados sobre Patrimônio Líquido, Lucro Líquido e Valor de Mercado em todos os períodos observados (de 2003 a 2007). Como o ano de 2008 ofereceu um dramático exemplo de crise financeira (JOHANSSON; DIMOFTE; MAZVANCHERYL, 2012), o estudo focou-se no período anterior à crise, uma vez que "o valor de mercado apresenta fortes variações diárias durante períodos de crise, criando ruídos nos dados" (JOHANSSON; DIMOFTE; MAZVANCHERYL, 2012, p. 6). Dessa forma, trabalhou-se com um total de 178 empresas.

Na terceira etapa, as ações dessas 178 empresas foram ordenadas de modo decrescente, de acordo com o seu Grau de Intangibilidade (GI) - a fórmula de cálculo apresentada na seção 2.3.1. Após essa ordenação, as empresas foram divididas pela mediana em duas categorias:

a) intangível-intensivas - empresas com Gl superior à mediana;

b) tangível-intensivas - empresas com Gl inferior à mediana.

$\mathrm{Na}$ quarta etapa, observaram-se somente as empresas que se mantiveram em cada um dos grupos mencionados, ou seja, aquelas que sempre foram intangíveis-intensivas e as que sempre foram tangíveis-intensivas, durante todo o período observado (de 2003 a 2008), totalizando 107 empresas. Após, essas 107 empresas foram novamente ordenadas de acordo com o Gl e foram divididas em quartis. Considerando-se o primeiro e o quarto quartis, formaram-se dois portfólios:

a) Sempre Intangível-Intensivas (SII) - empresas com maior GI durante todo o período (primeiro quartil);

b) Sempre Tangível-Intensivas (STI) - empresas com menor GI durante todo o período (quarto quartil).

Em outras palavras, ao final dessas etapas, obtiveram-se dois portfólios, o Sempre Intangível-Intensivas (SII), composto de 14 empresas, e o Sempre Tangível-Intensivas (STI), formado por 13 
empresas. Esses dois grupos foram, efetivamente, o objeto de análise estatística. Cumpre salientar que se optou pela divisão da amostra em quartis para diferenciar, claramente, os dois portfólios e por ser este um método de amostragem bastante utilizado em estudos similares na literatura de finanças, como no trabalho de Penman (1996), que também utilizou quartis em seu artigo.

Após a realização das quatro etapas, comparou-se a lista das empresas que compõem os portfólios SII e STI com o ranking das marcas brasileiras mais valiosas elaboradoras pela Brand Finance e Interbrand, para averiguar se os portfólios SII e STI apresentam marcas consideradas valiosas. Dentre as 14 empresas do portfólio SII, seis são consideradas com alto valor de marca, enquanto que, dentre as empresas STI, nenhuma é considerada com alto valor de marca (ver Tabela 3).

Tabela 3 - Relação de empresas que compõem os portfólios

\begin{tabular}{|c|c|c|c|}
\hline SII & $\begin{array}{c}\text { Presença em rankings de marcas } \\
\text { mais valiosas }\end{array}$ & STI & $\begin{array}{c}\text { Presença em rankings de marcas } \\
\text { mais valiosas }\end{array}$ \\
\hline $\begin{array}{l}\text { Lojas America- } \\
\text { nas }\end{array}$ & $\begin{array}{c}\text { Sim (Brand Finance, 2009, 2008, } \\
\text { 2007) }\end{array}$ & Wetzel S/A & Não \\
\hline Cia. Hering & Sim (Interbrand, 2010) & Tectoy & Não \\
\hline Bahema & Não & Docas & Não \\
\hline AES Tiete & $\begin{array}{c}\text { Sim (Brand Finance, 2009, 2008, } \\
\text { 2007) }\end{array}$ & Bombril & Não \\
\hline Portobello & Não & Minupar & Não \\
\hline Tam S/A & $\begin{array}{c}\text { Sim (Brand Finance, 2009, 2008, } \\
\text { 2007) }\end{array}$ & Recrusul & Não \\
\hline Besc & Não & Micheletto & Não \\
\hline Sousa Cruz & Não & Schlosser & Não \\
\hline CCR Rodovias & Não & $\begin{array}{l}\text { Pro Meta- } \\
\text { lurg }\end{array}$ & Não \\
\hline WEG & Não & Wiest & Não \\
\hline Ideiasnet & Não & Tecel S Jose & Não \\
\hline Vale Rio Doce & $\begin{array}{l}\text { Sim (Brand Finance, 2009, 2008, } \\
\text { 2007) }\end{array}$ & Caf Brasilia & Não \\
\hline Ambev & $\begin{array}{c}\text { Sim (Brand Finance 2009, 2008, } \\
\text { 2007) }\end{array}$ & \multirow[t]{2}{*}{ Sultepa } & \multirow[t]{2}{*}{ Não } \\
\hline lochp-Maxion & Não & & \\
\hline
\end{tabular}

Legenda: SII - Sempre Intangível-Intensivas; STI - Sempre Tangível-Intensivas.

\subsection{Medidas e variáveis}

Em continuidade, seguem descritas as medidas utilizadas neste estudo. Para calcular a Intangibilidade, foi utilizado o Gl; no cálculo do Desempenho Econômico, foram empregados Margem Operacional, Margem Líquida, Liquidez Corrente, Retorno sobre o Investimento (ROI) e o Beta (risco).

\subsubsection{Intangibilidade}

"A construção de uma definição adequada de ativos intangíveis é bastante complexa" (CARVALHO; KAYO; MARTIN, 2010, p. 876). Neste trabalho, compreende-se que a diferença entre o valor de uma empresa no mercado acionário e seu valor contábil representa os ativos intangíveis (LEV, 2001). A seguir, é descrita a variável adotada para determinar o grau de proporção que os ativos intangíveis representam dentro das empresas. 


\subsubsection{Grau de Intangibilidade}

Para calcular o GI das empresas, foi empregada a fórmula do valor de mercado dividido pelo valor contábil. A fórmula do Gl é, de acordo com Kayo (2002), apresentada na Equação 1:

$\mathrm{GI}=\mathrm{VMA} / \mathrm{PLC}$

Onde: $\mathrm{GI}=$ Grau de Intangibilidade, VMA = Valor de Mercado das Ações e PLC = Patrimônio Líquido Contábil

Este indicador de intangibilidade também foi utilizado por Lev (2001), Kayo e Famá (2004) e Machado e Fama (2011). O Gl é uma medida relativa, e, quanto maior, maior a participação relativa de ativos intangíveis na estrutura da empresa (KAYO, 2002, p. 17). O Valor de Mercado (VM) das Ações é calculado multiplicando-se as cotações das ações em circulação na data do último pregão do ano pela quantidade emitida. Essa fórmula é aceita por Damodaran (2007) e Pratt e Grabowski (2008) e foi utilizada por Kayo (2002) e Machado e Fama (2011). Para o cálculo do VM, utilizou-se o conceito do software Economática, que é a multiplicação entre o Total de Ações Outstanding e a cotação não ajustada por proventos. Já o Patrimônio Líquido Contábil (PLC) é um indicador do balanço patrimonial das empresas encontradas nos demonstrativos financeiros publicados, anualmente, por elas.

\subsection{2 Índices de Rentabilidade}

O Índice de Rentabilidade tem como objetivo "evidenciar os efeitos dos índices de liquidez, da atividade e de estrutura e de endividamento sobre os resultados obtidos pela empresa" (SCHMIDT; SANTOS; KLOCKNER, 2006, p. 76). De acordo com esses autores, o índice de rentabilidade está intimamente relacionado aos desempenhos econômicos das empresas, representando o retorno ou a rentabilidade dos recursos investidos e a eficiência de sua gestão. Os índices de rentabilidade utilizados por este estudo são apresentados a seguir.

\subsubsection{Retorno sobre o Investimento}

"O ROI representa o retorno sobre o capital próprio e de terceiros aplicados no empreendimento" (SAURIN et al., 2013). Conforme Assaf Neto (1997), essa medida, baseada em resultados provenientes da atividade objeto da empresa, quantifica o retorno produzido pelas decisões de investimento e permite que se proceda, com base nos valores apurados, a uma avaliação sobre a atividade econômica do empreendimento, definindo, inclusive, a atratividade do investimento e as condições de sua continuidade.

$\mathrm{ROI}=\mathrm{NOPAT} / \mathrm{Cl}$

Onde: $\mathrm{ROI}=$ Retorno sobre o Investimento, NOPAT = Net Operational Profit After Taxes (lucro operacional líquido após os impostos) e $\mathrm{Cl}=$ Capital Investido

\subsubsection{Margem Operacional}

A Margem Operacional é o índice que compara o resultado operacional da empresa com as vendas. Dessa forma, o referido índice evidencia a margem operacional proporcionada por cada unidade monetária de venda, isto é, a margem remanescente para o pagamento das despesas não operacionais da empresa (SCHMIDT; SANTOS; KLOCKNER, 2006). A margem 
operacional é fornecida pela Equação 3:

$\mathrm{MO}=\mathrm{RO} / \mathrm{RL}$

Onde: $\mathrm{MO}=$ Margem Operacional, $\mathrm{RO}=$ Resultado Operacional e RL = Receita Líquida

\subsubsection{Margem Líquida}

Segundo Schmidt, Santos e Klockner (2006), a Margem Líquida é obtida pela razão entre o lucro líquido do exercício e a receita líquida de vendas, evidenciando o lucro proporcionado por cada unidade monetária de venda. A margem líquida é encontrada via Equação 4:

$\mathrm{ML}=\mathrm{LLE} / \mathrm{RL}$

Onde: $M L=$ Margem Líquida, LLE =Lucro Líquido do Exercício, e RL = Receita Líquida

\subsection{3 Índices de liquidez}

Em consonância com Schmdit, Santos e Klockner (2006), os índices que compõem as informações a respeito da liquidez das empresas são utilizados, mais comumente, para concessão de crédito, já que não importa somente o montante de obrigações que a empresa possui, mas também se ela será capaz de pagar o empréstimo no prazo contratado.

\subsubsection{Liquidez Corrente}

A Liquidez Corrente é o índice que compara os bens e os direitos que se converterão em dinheiro em até 12 meses com as obrigações de igual prazo (SCHMIDT; SANTOS; KLOCKNER, 2006). Ainda conforme os autores, o índice de liquidez corrente (Equação 5) é a medida de solvência de curto prazo mais utilizada pelas empresas.

$\mathrm{LC}=\mathrm{AC} / \mathrm{PC}$

Onde: $\mathrm{LC}=$ Liquidez Corrente, $\mathrm{AC}=$ Ativo Circulante, e PC = Passivo Circulante

\subsubsection{Medidas de desempenho de mercado}

\subsubsection{Beta (risco)}

Segundo Rochman (2009), o Beta examina o risco da ação em relação a um determinado mercado acionário, que, por sua vez, é representado por algum índice de bolsa de valores, como, por exemplo, o IBOVESPA, o IBrX e o FGV-100. Devido à propagação de serviços de dados sobre o mercado acionário, o Beta das empresas analisadas pode ser obtido diretamente no software Economática:.

\subsection{Análise dos dados}

Após a realização da coleta de dados e do teste estatístico, procedeu-se à análise dos resultados. Foram examinados os dados das 27 empresas divididas em dois portfólios, com base na mediana do GI destas - as Sempre Intangível-Intensivas (SII) e as Sempre Tangível-Intensivas (STI). Compararam-se os dois portfólios pelos resultados dos testes Mann-Whitney para cada variável, ou seja, os seus indicadores de desempenho econômico (Margem Operacional, Margem Líquida, Liquidez Corrente, Retorno sobre o Investimento e o Beta) em cada período. A variação 
entre o número de empresas $(\mathrm{N})$ para cada variável em cada período ocorreu devido à falta de informações de algumas empresas para certo ano ou variável.

No presente estudo, o portfólio com a maior amostra (Sempre Tangível-Intensivas) foi tratado como " $\mathrm{n} 2$ " e o grupo de menor amostra (Sempre Intangível-Intensivas) foi tratado como "n1". Utilizou-se o software SPPS para obter o $U$ de Mann-Whitney, para, na sequência, compará-lo com os valores críticos da tábua K. Em conformidade com Siegel (1975), quando um valor observado de $U$, para $\mathrm{n} 1 \leq 20$ e $9 \leq \mathrm{n} 2 \leq 20$, não exceder o valor fornecido pela tábua $K$, rejeitase a hipótese nula, ao nível de significância que for indicado na tábua. $\mathrm{O}$ nível de significância utilizado no estudo foi $\alpha<0,05$; dado que a Hipótese Alternativa representa uma não igualdade, empregou-se a análise bilateral para o nível de significância anteriormente mencionado.

\section{RESULTADOS}

\subsection{Margem Operacional}

Com relação aos resultados encontrados para a variável de Margem Operacional (Tabela $4)$, em todos os anos estudados ( $100 \%$ dos casos), o resultado do teste $U$ obteve valor inferior aos valores críticos da tábua K. Assim, para todo o período, os resultados foram significativos $(\alpha<0,05)$.

Tabela 4 - Resultados da Margem Operacional

\begin{tabular}{|c|c|c|c|c|c|}
\hline Ano & Portfólio & $\mathrm{N}$ & Média dos Postos & $U$ & Sig. 2-tailed \\
\hline \multirow{2}{*}{2003} & Sempre Tangível-Intensivas & 13 & 8,62 & \multirow{2}{*}{21,000} & \multirow{2}{*}{0,002} \\
\hline & Sempre Intangível-Intensivas & 12 & 17,75 & & \\
\hline \multirow{2}{*}{2004} & Sempre Tangível-Intensivas & 13 & 7,35 & \multirow{2}{*}{4,500} & \multirow{2}{*}{0,000} \\
\hline & Sempre Intangível-Intensivas & 11 & 18,59 & & \\
\hline \multirow{2}{*}{2005} & Sempre Tangível-Intensivas & 13 & 7,46 & \multirow{2}{*}{6,000} & \multirow{2}{*}{0,000} \\
\hline & Sempre Intangível-Intensivas & 11 & 18,45 & & \\
\hline \multirow{2}{*}{2006} & Sempre Tangível-Intensivas & 13 & 8,15 & \multirow{2}{*}{15,000} & \multirow{2}{*}{0,001} \\
\hline & Sempre Intangível-Intensivas & 11 & 17,64 & & \\
\hline \multirow{2}{*}{2007} & Sempre Tangível-Intensivas & 13 & 8,85 & \multirow{2}{*}{24,000} & \multirow{2}{*}{0,002} \\
\hline & Sempre Intangível-Intensivas & 13 & 18,15 & & \\
\hline
\end{tabular}

Além disso, o portfólio das empresas Sempre Intangível-Intensivas (SII) alcançou médias maiores do que o das Sempre Tangível-Intensivas (STI). A Figura 3 ilustra essa situação.

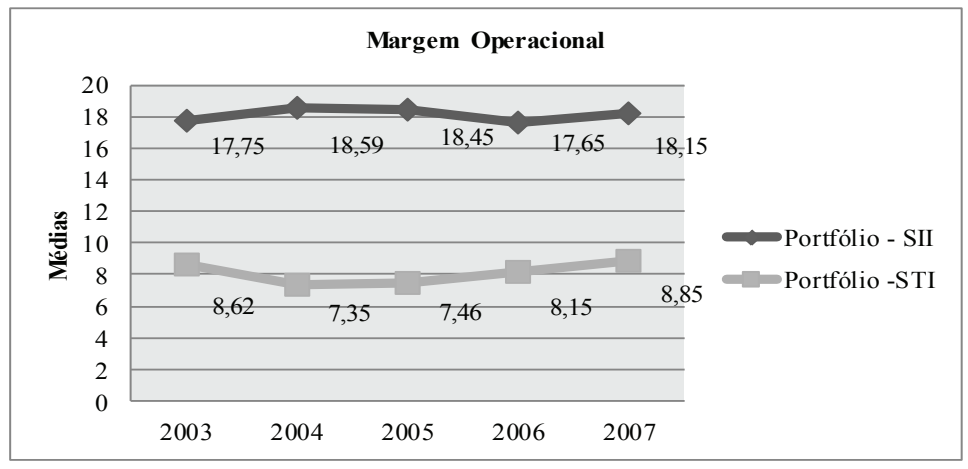

Figura 3 - Médias da Margem Operacional dos portfólios 


\subsection{Margem Líquida}

Analisando os resultados a respeito da margem líquida nos cinco anos pesquisados (Tabela 5), verifica-se que, em $100 \%$ dos casos, o resultado do teste $U$ foi inferior aos valores críticos da tábua K. Consequentemente, os resultados encontrados para essa variável foram todos significativos.

Tabela 5 - Resultados da Margem Líquida

\begin{tabular}{|c|c|c|c|c|c|}
\hline Ano & Portfólio & $\mathrm{N}$ & Média dos Postos & $U$ & Sig. 2-tailed \\
\hline \multirow{2}{*}{2003} & Sempre Tangível-Intensivas & 13 & 8 & \multirow{2}{*}{13,000} & \multirow{2}{*}{0,000} \\
\hline & Sempre Intangível-Intensivas & 13 & 19 & & \\
\hline \multirow{2}{*}{2004} & Sempre Tangível-Intensivas & 13 & 7,23 & \multirow{2}{*}{3,000} & \multirow{2}{*}{0,000} \\
\hline & Sempre Intangível-Intensivas & 12 & 19,25 & & \\
\hline \multirow{2}{*}{2005} & Sempre Tangível-Intensivas & 13 & 7,54 & \multirow{2}{*}{7,000} & \multirow{2}{*}{0,000} \\
\hline & Sempre Intangível-Intensivas & 12 & 18,92 & & \\
\hline \multirow{2}{*}{2006} & Sempre Tangível-Intensivas & 13 & 8,23 & \multirow{2}{*}{16,000} & \multirow{2}{*}{0,001} \\
\hline & Sempre Intangível-Intensivas & 12 & 18,17 & & \\
\hline \multirow{2}{*}{2007} & Sempre Tangível-Intensivas & 13 & 8,42 & \multirow{2}{*}{18,500} & \multirow{2}{*}{0,000} \\
\hline & Sempre Intangível-Intensivas & 14 & 19,18 & & \\
\hline
\end{tabular}

Acrescente-se, ainda, que o portfólio das empresas SIl obteve médias maiores que o das STI, como pode ser observado na Figura 4.

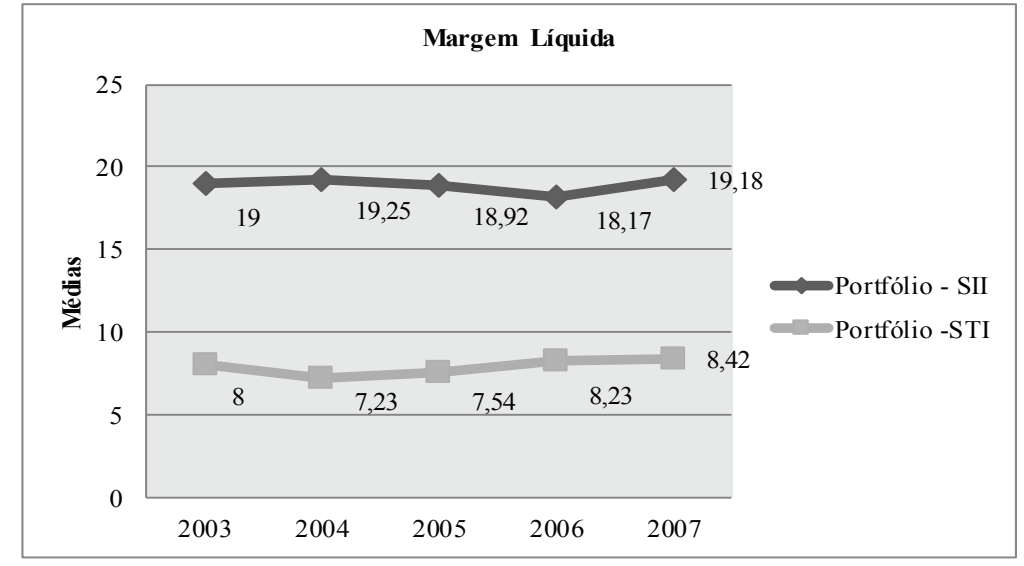

Figura 4 - Média da Margem Líquida dos portfólios

\subsection{Liquidez Corrente}

A respeito da Liquidez Corrente das empresas estudadas no período (Tabela 6), observou-se que o grupo das SII, em $80 \%$ dos casos estudados (cinco anos), obteve o valor do $U$ abaixo dos valores críticos da tábua $\mathrm{K} \mathrm{e}$, em apenas um caso (20\%), obteve o valor de $U$ acima dos valores da tábua K. Tal resultado indica que somente este caso, que corresponde ao ano de 2003, não foi significativo. Nos demais períodos, foram encontrados resultados significativos. 
Tabela 6 - Resultados da Liquidez Corrente

\begin{tabular}{|c|c|c|c|c|c|}
\hline Ano & Portfólio & $\mathrm{N}$ & Média dos Postos & $U$ & Sig. 2-tailed \\
\hline \multirow{2}{*}{2003} & Sempre Tangíveis-Intensivas & 13 & 11,04 & \multirow{2}{*}{52,500} & \multirow{2}{*}{0,061} \\
\hline & Sempre Intangíveis-Intensivas & 14 & 16,75 & & \\
\hline \multirow{2}{*}{2004} & Sempre Tangíveis-Intensivas & 13 & 9,31 & \multirow{2}{*}{30,000} & \multirow{2}{*}{0,003} \\
\hline & Sempre Intangíveis-Intensivas & 14 & 18,36 & & \\
\hline \multirow{2}{*}{2005} & Sempre Tangíveis-Intensivas & 13 & 8,92 & \multirow{2}{*}{25,000} & \multirow{2}{*}{0,001} \\
\hline & Sempre Intangíveis-Intensivas & 14 & 18,71 & & \\
\hline \multirow{2}{*}{2006} & Sempre Tangíveis-Intensivas & 13 & 8,69 & \multirow{2}{*}{22,000} & \multirow{2}{*}{0,001} \\
\hline & Sempre Intangíveis-Intensivas & 14 & 18,93 & & \\
\hline \multirow{2}{*}{2007} & Sempre Tangíveis-Intensivas & 13 & 9,19 & \multirow{2}{*}{28,500} & \multirow{2}{*}{0,002} \\
\hline & Sempre Intangíveis-Intensivas & 14 & 18,46 & & \\
\hline
\end{tabular}

O portfólio das empresas SII apresentou resultados superiores em suas médias do índice de liquidez ao portfólio das empresas STI. No ano de 2003, foi encontrada a menor diferença entre os portfólios, sendo a média de liquidez corrente das SII 38,32\% maior que a das STI. Contudo, no ano de 2006, foi encontrada a maior diferença do período estudado, com a média da liquidez corrente das SII 358,82\% maior que a das STI. Em geral, a média do portfólio das empresas SII foi $165,79 \%$ maior que a do portfólio das empresas STI (Figura 5).

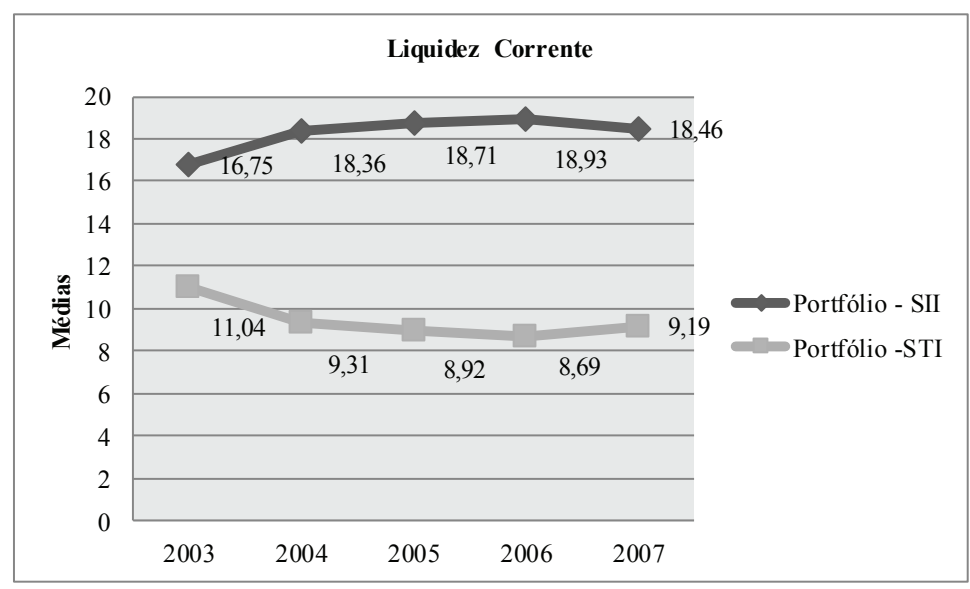

Figura 5 - Média da Liquidez Corrente dos portfólios

\subsection{Retorno sobre o Investimento}

Verificando os resultados a respeito do ROI (Tabela 7), conclui-se que, em $100 \%$ dos períodos estudados, o valor de $U$ obtido é superior aos valores críticos da tábua $\mathrm{K}$, o que indica nenhum resultado significativo.

Tabela 7 - Resultados do Retorno sobre o Investimento (ROI)

\begin{tabular}{cccccc}
\multirow{2}{*}{ Ano } & Portfólio & N & Média dos Postos & U & Sig. 2-tailed \\
\multirow{2}{*}{2003} & Sempre Tangíveis-Intensivas & 13 & 13,62 & \multirow{2}{*}{86,000} & 0,808 \\
\cline { 2 - 4 } 2004 & Sempre Intangíveis-Intensivas & 14 & 14,36 & & \\
& Sempre Tangíveis-Intensivas & 13 & 12,92 & 77,000 & 0,497
\end{tabular}




\begin{tabular}{cccccc}
\hline \multirow{2}{*}{ Ano } & Portfólio & N & Média dos Postos & $U$ & Sig. 2-tailed \\
\multirow{2}{*}{2005} & Sempre Tangíveis-Intensivas & 13 & 11,92 & 64,000 & 0,19 \\
& Sempre Intangíveis-Intensivas & 14 & 15,93 & & \multirow{2}{*}{0,109} \\
\multirow{2}{*}{2006} & Sempre Tangíveis-Intensivas & 13 & 11,46 & 16,36 & \multirow{2}{*}{0,56} \\
& Sempre Intangíveis-Intensivas & 14 & 13,08 & 70,000 & 0,56 \\
\hline
\end{tabular}

No cálculo das médias, o portfólio das empresas SIl evidenciou valores maiores do que o das STI. Porém, essa diferença foi razoavelmente pequena, o que contribuiu para o resultado não ser significante. A Figura 6, exposta a seguir, ilustra essa situação descrita.

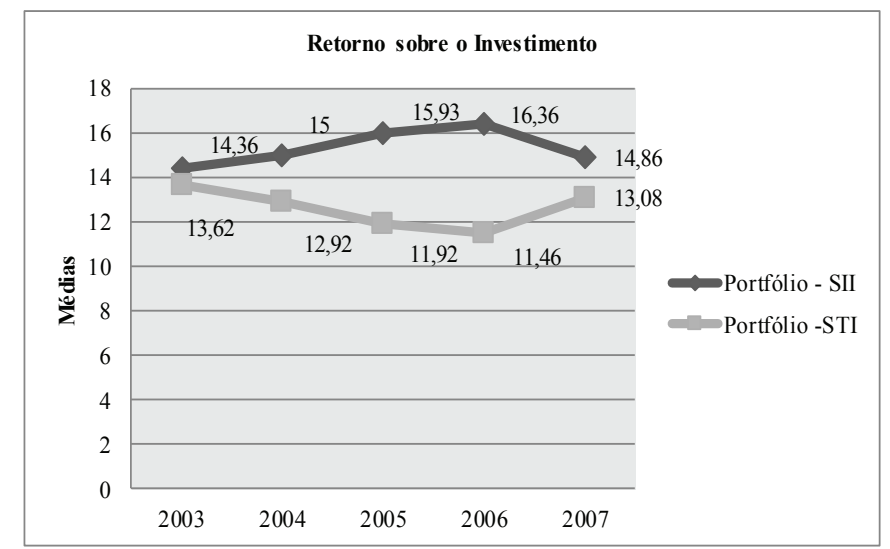

Figura 6 - Média do Retorno sobre o Investimento dos portfólios

\subsection{Beta}

A respeito do Beta dos portfólios estudados (Tabela 8), verificou-se que o valor de $U$ encontrado é superior aos valores críticos da tábua $\mathrm{K}$, indicando que nenhum resultado foi significativo.

Tabela 8 - Resultados do Beta

\begin{tabular}{|c|c|c|c|c|c|}
\hline Ano & Portfólio & $\mathrm{N}$ & Média dos Postos & $U$ & Sig. 2-tailed \\
\hline \multirow{2}{*}{2003} & Sempre Tangíveis-Intensivas & 8 & 10,5 & \multirow{2}{*}{32,000} & \multirow{2}{*}{0,476} \\
\hline & Sempre Intangíveis-Intensivas & 10 & 8,7 & & \\
\hline \multirow{2}{*}{2004} & Sempre Tangíveis-Intensivas & 10 & 11,25 & \multirow{2}{*}{52,500} & \multirow{2}{*}{0,86} \\
\hline & Sempre Intangíveis-Intensivas & 11 & 10,77 & & \\
\hline \multirow{2}{*}{2005} & Sempre Tangíveis-Intensivas & 10 & 11,9 & \multirow{2}{*}{64,000} & \multirow{2}{*}{0,95} \\
\hline & Sempre Intangíveis-Intensivas & 13 & 12,08 & & \\
\hline \multirow{2}{*}{2006} & Sempre Tangíveis-Intensivas & 10 & 12,45 & \multirow{2}{*}{50,500} & \multirow{2}{*}{0,53} \\
\hline & Sempre Intangíveis-Intensivas & 12 & 10,71 & & \\
\hline \multirow{2}{*}{2007} & Sempre Tangíveis-Intensivas & 13 & 11,12 & \multirow{2}{*}{53,500} & \multirow{2}{*}{0,112} \\
\hline & Sempre Intangíveis-Intensivas & 13 & 15,88 & & \\
\hline
\end{tabular}


Ao analisar as médias para o Beta, percebe-se que, em $40 \%$ dos casos (nos anos de 2003, 2004 e 2006), o portfólio das empresas STI apresentou valor superior ao das empresas $\mathrm{SII}$, ou seja, em $40 \%$ do período analisado, as empresas com menor GI da amostra evidenciaram maiores riscos de mercado. Nos demais casos (60\%), as médias do portfólio SII foram maiores. É possível observar essa situação na Figura 7.

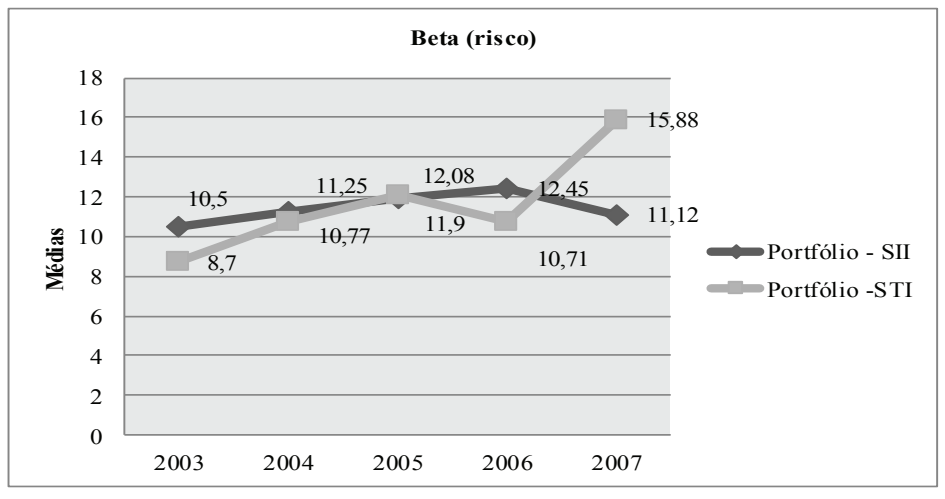

Figura 7 - Média do Beta dos portfólios

\subsection{Médias e comparações entre portfólios}

O presente estudo conseguiu alcançar o seu objetivo ao verificar a diferença de desempenho econômico entre portfólios de empresas presentes no mercado acionário brasileiro, formados a partir de seu GI. Essa diferença pode ser constatada na Tabela 9, a qual apresenta um resumo dos principais achados da pesquisa.

Tabela 9 - Comparação dos resultados

\begin{tabular}{|c|c|c|c|c|c|c|}
\hline $\begin{array}{l}\text { Principais resultados (cinco } \\
\text { anos) }\end{array}$ & $\begin{array}{c}\text { Margem } \\
\text { Operacional }\end{array}$ & $\begin{array}{l}\text { Margem } \\
\text { Líquida }\end{array}$ & $\begin{array}{l}\text { Liquidez } \\
\text { Corrente }\end{array}$ & $\begin{array}{l}\text { Retorno sobre } \\
\text { o investimento }\end{array}$ & Beta & Portfólio \\
\hline \multirow{2}{*}{$\begin{array}{c}\text { Porcentagem nos cinco anos } \\
\text { cuja média dos postos de um } \\
\text { portfólio é superior à média } \\
\text { do outro }\end{array}$} & $0 \%$ & $0 \%$ & $0 \%$ & $0 \%$ & $40 \%$ & STI \\
\hline & $100 \%$ & $100 \%$ & $100 \%$ & $100 \%$ & $60 \%$ & SII \\
\hline \multirow{2}{*}{ Média geral } & 8,1 & 7,89 & 9,43 & 12,6 & 11,44 & STI \\
\hline & 18,11 & 18,90 & 18,24 & 15,39 & 11,63 & SII \\
\hline
\end{tabular}

De acordo com a Tabela 9, pode-se auferir que o portfólio das empresas SIl possui meIhor desempenho econômico na maioria dos períodos analisados. Conforme se verifica, a média dos postos de todos os indicadores foi superior para o portfólio das SII em relação ao outro portfólio estudado. Os autores Wagner, Motta e Dornelles (2004) afirmam que, "quando a média dos postos de um grupo for maior, este possuirá um resultado mais significante". Essa afirmação vai ao encontro dos resultados obtidos para as variáveis Margem Operacional, Margem Líquida e Liquidez Corrente, o que condiz com a literatura que cita a presença de ativos intangíveis como contribuinte para a obtenção de vantagens competitivas (PEREZ; FÁMA, 2006a).

Apesar de o portfólio das empresas SII ter obtido valores maiores de $\mathrm{ROI}$ em relação às $\mathrm{STI}$, as diferenças foram pequenas e não significantes. Também não foram encontrados resultados significativos para o Beta. Contudo, verificou-se que o portfólio das empresas consideradas SIl obteve desempenho sempre superior ao das empresas STI em quatro das seis variáveis. Esses 
resultados têm como consequência a rejeição da hipótese nula deste artigo, corroborando a afirmação da literatura existente de que há diferenças no desempenho econômico dos portfólios de acordo com o GI das suas empresas.

Em pesquisa semelhante, Villalonga (2004) testou a hipótese segundo a qual, quanto maior o Gl dos recursos da empresa (mensurado via o q de Tobins), maior é a sustentabilidade de sua vantagem competitiva. Seu estudo demonstrou "que intangíveis desempenham um papel eficaz na manutenção da vantagem competitiva de uma empresa, como previsto pela visão baseada em recursos da empresa" (VILLALONGA, 2004, p. 205). Os resultados do presente estudo também vão ao encontro dos achados da pesquisa de Perez e Famá (2006b), realizada no mercado acionário norte-americano, que demonstrou a relevância dos ativos intangíveis para o desempenho econômico da empresa. Para os autores, quanto maior a parcela de ativos intangíveis, maior a geração de valor para os acionistas.

Além disso, reconhece-se que muitos ativos intangíveis dessas empresas são oriundos de seus esforços mercadológicos. O portfólio SII é composto por empresas que, em geral, apresentam elevado valor da marca (um dos principais ativos intangíveis das organizações - fruto das ações de marketing). Várias dessas marcas, inclusive, são as mais valiosas do Brasil, estando presentes nos rankings brasileiros de marcas mais valiosas da Brand Finance e Interbrand.

No presente estudo, justamente o portfólio que apresenta a maior quantidade de marcas valiosas é o que mostra os melhores desempenhos empresariais ao longo dos períodos analisados, apontando para possíveis associações dos esforços de marketing com o desempenho da firma.

Destaca-se que, normalmente, as empresas apenas tecem associações entre os esforços de marketing e o desempenho em vendas, dado que isso é mais fácil de visualizar e contabilizar. Porém, grande parte da ação de marketing recai sobre a construção de ativos intangíveis para a firma - valor da marca, valor do cliente, relacionamento etc. -, e os progressos nessas áreas não são facilmente verificados (SRINIVASAN; HANSSENS, 2009) devido à própria natureza dos ativos intangíveis.

Pesquisas anteriores na área de marketing já mostram evidências das possíveis relações entre os esforços de marketing e, consequentemente, os ativos intangíveis mercadológicos, de forma isolada, com o desempenho econômico-financeiro, que são: marcas valiosas com o desempenho da empresa (MIZIK; JACOBSON, 2008; MIZIK; JACOBSON, 2009; OLIVEIRA, 2009; STAHL et al., 2012); marca e pesquisa \& desenvolvimento com o valor de mercado da firma (SANDERS; BLOCK, 2011); valor do cliente com valor da firma (GUPTA; LEHMANN; STUART 2004; HANSSENS; RUST; SRIVASTAVA, 2009; GOLEC; GUPTA, 2014).

Apesar de a "literatura empírica sobre a natureza desse relacionamento estar crescendo, ainda está em sua infância em muitos aspectos" (FORNELL et al., 2006, p. 4). Nesse contexto, os acadêmicos e práticos de marketing estão sob crescente pressão para se aproximarem das áreas de finanças e contabilidade (RUST et al., 2004). Pela via da demonstração da relevância dos ativos intangíveis, oriundos em grande parte das ações da área de marketing, o presente estudo permite predizer uma possível associação entre os esforços dessa área e o desempenho econômico-financeiro das organizações.

\section{CONSIDERAÇÕES FINAIS}

Ao avaliar, empiricamente, a relevância dos ativos intangíveis em relação aos bens tangíveis, no contexto do mercado acionário brasileiro, a presente pesquisa traz uma informação relevante, pois demonstra que existem diferenças no desempenho econômico dos portfólios formados de acordo com o Grau de Intangibilidade (GI) das empresas que os compõem. Con- 
cluiu-se, desse modo, que os ativos intangíveis podem contribuir para a obtenção de vantagens competitivas, uma vez que as empresas com maior proporção de ativos intangíveis apresentam crescimento mais rápido de Margem Líquida, Margem Operacional e Liquidez Corrente.

Nesse contexto, o presente estudo agrega um passo na busca pela averiguação da importância dos ativos intangíveis, ao apontar que o portfólio de maior Gl apresenta desempenho econômico superior ao portfólio de maior tangibilidade, na maioria das variáveis e dos períodos observados. Assim, pode-se afirmar que este estudo empírico acerca do mercado acionário brasileiro auxilia a suportar os insights teóricos da Visão Baseada em Recursos (Resource Based View - RBV).

Além disso, este estudo se faz relevante para a valorização da área de marketing, dado que os resultados permitem inferir uma possível associação entre os esforços dessa área na construção dos ativos intangíveis de uma organização, como o valor da marca, e a melhoria do desempenho econômico-financeiro.

Acredita-se, ainda, que os resultados encontrados são importantes para o contexto brasileiro, visto que existem poucos trabalhos no Brasil a respeito desse tema. Dentre as implicações gerenciais, ressalta-se a consequente pertinência de as empresas, principalmente as Sociedades Anônimas (S.As), buscarem observar e avaliar tais recursos, especialmente em um cenário de nova legislação contábil, com a recomendação de seguir os padrões internacionais de contabilização dos intangíveis.

Entre as limitações desta pesquisa, no entanto, encontra-se a forma simplista de mensurar os ativos intangíveis, pois, apesar de já ter sido utilizada em vários trabalhos acadêmicos, a variável GI pode não identificar por completo a proporção de ativos intangíveis em uma empresa, visto que a identificação destes é considerada complexa (FÁMA, 2006). Porém, deve-se ressalvar que ela é a mais indicada para esse tipo de análise.

Além disso, também devem ser consideradas as imperfeições do mercado brasileiro, como a excessiva concentração nas mãos de poucos players, os problemas de liquidez e a alta volatilidade (FÁMA, 2006). O fato de ter sido utilizado um período abrangente (cinco anos) permite uma visão de continuidade, não somente uma fotografia do momento. Assim, particularidades como influência de especulações no preço da ação são dirimidas pelo número de anos estudados.

Sugere-se, para futuras pesquisas, efetuar similar estudo, com a utilização de outros períodos de análise ou, inclusive, períodos mais abrangentes, outra medida de intangibilidade e/ou outras variáveis de desempenho financeiro e de mercado. Também é possível efetuar a mesma pesquisa em outros mercados, para estabelecer um comparativo entre os resultados encontrados no Brasil e em outros países. 


\section{REFERÊNCIAS}

AAKER, D.A.; JACOBSON, R. The value relevance of brand attitude in high-technology markets. Journal of Marketing Research, v.38, n.4, p. 485-493, 2001.

AKSOY, L.; COOIL, B.; GROENING, C.; KEININGHAM, T. L.; YALÇIN, A. The LongTerm Stock Market Valuation of Customer Satisfaction. Journal of Marketing, v. 72, p. 105-122, 2008.

AMBLER, T. Marketing and the bottom line. Harlow: Prentice Hall, 2003.

ASSAF NETO, A. A dinâmica das decisões financeiras. Caderno de Estudos, 16, p. 01-17, 1997.

BARNEY, J. Firm resources and sustained competitive advantage. Journal of Management, v.17, n.1, p. 99-120, 1991.

BARTH, M. E.; CLINCH, G. Revalued financial, tangible, and intangible assets: associations with share prices and non-market-based value estimates. Journal of Accounting Research, v.36, n.3, p.199-233, 1998.

BOLSA DE VALORES DE SÃO PAULO. Mercados. 2010. Disponível em: < http://www. bmfbovespa.com.br/home.aspx?idioma=ptbr>. Acesso em: 04 jul. 2010.

BRAND FINANCE. Brand Values in a Recession. 2008. Disponível em: < http:// www.brandfinance.com/ Uploads/pdfs/ Top100UpdateReport.pdf.>. Acesso em: 6 maio 2010.

BRODIE, R. J.; GLYNN, M. S.; DURME, J. V. Thinking with Financial Thinking Towards a Theory of Marketplace Equity: Integrating Branding and Relationship. Marketing Theory, v.2, n.5, p. 5-28, 2002.

CARMELI, A. High- and low-performance firms: do they have different profiles of perceived core intangible resources and business environment? Technovation, 21, p. 661-67, 2001.

CARMELI, A.; TISHLER, A. The relationships between intangible organizational elements and organizational performance. Strategic Management Journal, v.25, n.13, p. 12571278, 2004.

CARVALHO, F. de M.; KAYO, E. K.; MARTIN, D. M. L. Tangibilidade e Intangibilidade na Determinação do Desempenho Persistente de Firmas Brasileiras. RAC, Curitiba, v. 14, n. 5, art. 6, p. 871-889, Set./Out. 2010.

CHIABI, Ana Luiza Gontijo; GONÇALVES, Carlos Alberto. Análise de estratégia de mudança da marca acrescentando valor: um estudo da VALE. REA - Revista de Administração da UFSM, v. 3, n. 1, p. 131-143, 2010.

DAMOdaran, A. Avaliação de Empresas. 2. ed. São Paulo: Pearson, 2007.

DELIOS, A.; BEAMISH, P. W. W. Survival and Profitability: The Roles of Experience and Intangible Assets in Foreign Subsidiary Performance. 2002. Disponível em: < http:// dx.doi.org/10.2139/ssrn.305345>. Acesso em: 10 jun. 2010.

HANSSENS, D.; RUST, R.T.; SRIVASTAVA, R. K. Marketing strategy and Wall Street: nailing down marketing's impact. Journal of Marketing, v.73, p.115-118, Nov 2009.

FISHER, M. Valuing Brand Assets: a costeffective and easy-to-implement measurement approach. MSI Reports, Cambridge, 2007.

FORNELL, C. S. M.; MORGESON, F. V.; KRISHNAN, M. S. Customer satisfaction and stock prices: high returns, low risk. Journal of Marketing, v.70, p. 3-14, Jan 2006.

GITMAN, L. J. Princípios da Administração Financeira. (10a ed.). São Paulo: Pearson Addison Wesley, 2004. 
GOLEC, J.; GUPTA, N. J. Do investments in intangible customer assets affect firm value? The Quarterly Review of Economics and Finance, v. 54, p. 513-520, 2014.

HIGGINS, H. Can securities analysts forecast intangible firms' earnings? International Journal of Forecasting, v.29, n.1, p. 155-174, Jan-Mar 2013.

HONORATO, H. G. A influência dos ativos intangíveis na análise de risco de crédito de empresas de base tecnológica. Dissertação de Mestrado, Programa de Pós- Graduação em Gestão Empresarial, Fundação Getúlio Vargas, São Paulo, SP, BR, 2008.

IASC FOUNDATION. Summaries of International Financial Reporting Standards. 2008. Disponível em: <http://www.iasplus.com/standard/ias38. htm.>. Acesso em: 3 maio 2010.

INTERBRAND. Brand Valuation: the financial value of the brands. 2004. Disponivel em: <http://www.brandchannel.com/images/ papers/financial_value.pdf $>$. Acesso em: 3 jul. 2010.

INTERBRAND. $O$ Poder das Marcas na América Latina. 2008. Disponível em: <http:// www.interbrand.com/images/studies/O_ Poder_das_Marcas_na_Am\%C3\%A9rica_ Latina_2008.pdf>. Acesso em: 20 jul. 2010.

INTERBRAND. Ranking Interbrand das marcas mais valiosas. 2010. Disponível em: <http:// www.interbrand.com/images/studies/-1_ Best_Brazilian_Brands_2010_portuguese. pdf>. Acesso em: 02 ago. 2010.

IRL, A. C. Como elaborar projetos de pesquisa. (4a ed.). São Paulo: Atlas, 2009.

JOHANSSON, J. K.; DIMOFTE, C. V.; MAZVANCHERYL, S. K. The performance of global brands in the 2008 financial crisis: A test of two brand value measures. International Journal of Research in Marketing, v. 29, n. 3, p. 235-245, 2012.
KAYO, E. K. A estrutura de capital e o risco das empresas tangível e intangível-intensivas: uma contribuição ao estudo da valoração de empresas. Tese de Doutorado, Faculdade de Economia, Administração e Contabilidade da Universidade de São Paulo, 2002.

KAYO, E. K.; FAMÁ, R. A estrutura de capital e o risco das empresas tangível-intensivas e intangível-intensivas. Revista de Administração da USP, v. 39, n.2, p. 164-176, 2004.

KAYO, E.; KIMURA, H.; LEIVA, D. M.; NAKAMURA, W. Ativos Intangíveis, Ciclo de Vida e Criação de Valor. RAC, v.10, n.3, p.73-90, 2006.

KELLER, K. L. Strategic brand management: building, measuring, and managing brand equity. New Jersey: Prentice Hall, 1998.

LEHMANN, D. R. Linking marketing to financial performance and firm value. Journal of Marketing, v. 68, p. 73-75, 2004

LEV, B. Intangibles: management and reporting. Washington: Brookings, 2001.

LIN, G. T. R.; TANG, J. Y. H. Appraising intagible assets from the viewpoint of value drivers. Journal of Business Ethics, 88, p. 679-689, 2009.

LUSCH, R.; MICHAEL, G. Opinion: The Case for an Off-Balance-Sheet Controller. Sloan Management Review, 35(winter), 101-105, 1984.

MACHADO, J. H.; FAMÁ, R. Ativos Intangíveis e Governança Corporativa no Mercado de Capitais Brasileiro. Revista Contemporânea de Contabilidade, v. 8, n. 16, p. 89-110, 2011.

MANTOVANI, E. F. V.; SANTOS, F. A. A contabilização do ativo intangível nas 522 empresas listadas na BM\&FBOVESPA. Revista de Administração e Inovação, São Paulo, v. 11, n .3, p .311-328, 2014.

MARKETING SCIENCE INSTITUTE. Current Research Priorities. 2009. Disponível em: 
<http://www.msi.org/research/ cfm?id=43. $>$. Acesso em: 15 set. 2009.

MARKETING SCIENCE INSTITUTE (MSI). 2012-2014 Research Priorities. Disponível em: $\quad<$ http://www.msi.org/research/index. cfm?id=338>. Acesso em: ago 2012.

MIZIK, N.; JACOBSON, R. The financial value impact of perceptual brand attributes. Journal of Marketing Research, XLV, 15-32, 2008.

MIZIK, N.; JACOBSON, R. Valuing branded businesses. Journal of Marketing, v.73, n.6, p. 137-153, 2009.

OLIVEIRA, M. R. O Valor da Marca e o Valor ao Acionista em Empresas Brasileiras. 2009. Dissertação (Mestrado em Administração) Universidade Federal do Rio Grande do Sul, Porto Alegre, RS, BR, 2009.

PENMAN, S. H. The articulation of priceearnings ratios and market-to-book ratios and the evaluation of growth. Journal of Accounting Research, v.34, n.2, p.235-59, 1996.

PEREZ, M.; FAMÁ, R. Ativos intangíveis e o desempenho empresarial. Revista Contabilidade Financeira - USP, n.40, v.17, p. $7-24,2006 a$.

PEREZ, M.; FAMÁ, R. Características estratégicas dos ativos intangíveis e o desempenho econômico da empresa. eGesta - Revista Eletrônica de Gestão e Negócios, v.2, n.2, p. 69-96, 2006b.

PRATT, S. P.; GRABOWSKI, R. J. Cost of capital: Applications and Examples. 3. ed. Nova Jersey: Wiley, 2008.

REILLY, R. F.; SCHWEIS, R. P. Valuing intangible assets. New York: McGraw-Hill, 1998.

REGO, B. B.; OLIVEIRA, M. O. R.; LUCE, F. B. Uma discussão teórica da relação do valor da marca e do valor do cliente. REA - Revista de Administração da UFSM, Santa Maria, v. 1, n. 2, p. $275-290,2008$.
ROCHMAN, R. R. O CAPM (Parte Final) Beta. 2009 Disponível em: <http://web. infomoney.com.br/templates/news/view. asp?codigo=1695831\&path=/investimentos/ noticias/colunistas $>$. Acesso em: $<20$ jul. 2010.

RUST, R.T.; AMBLER, T.; CARPENTER, G. S.; KUMAR, V.; SRIVASTAVA, R. K. Measuring Marketing Productivity: Current Knowledge and Future Directions. Journal of Marketing, $v$. 68, p. 76-89, Oct 2004.

SANDNER, Philipp G.; BLOCK, Joern. The market value of R\&D, patents, and trademarks. Research Policy, v. 40, n. 7, p. 969985, 2011.

SAURIN, Valter et al. Medidas de eficiência e retorno de Investimento: um estudo nas distribuidoras de energia elétrica brasileiras com base em Data Envelopment Analysis, Índice de Malmquist e ROI. Revista de Administração da UFSM, v. 6, n. 1, p. 25-38, 2013.

SCHIMIDT, P.; SANTOS, J. L.; KLOECKNER, G. Avaliação de Empresas: foco na gestão de valor das empresas: teoria e pratica. São Paulo: Atlas, 2006.

SIEGEL, S. Estatística não paramétrica para as ciências do comportamento. São Paulo, McGraw-Hill do Brasil, 1971.

SRINIVASAN, S.; HANSSENS, D. Marketing and Firm Value: metrics, methods, findings, and future directions. Journal of Marketing Research, v. XLVI, p. 293-312, 2009.

SRIVASTAVA, R. K. S.; SHERVANI, T. A.; FAHEY, L. Marketing, business processes, and shareholder value: an organizationally embedded view of marketing activities and the discipline of marketing. Journal of Marketing, v. 63, special issue, p. 168-179, 1999.

SRIVASTAVA, R. K. S.; SHERVANI, T. A.; FAHEY, L. Market-based Assets and shareholder value: a framework for analysis. Journal of Marketing, v.62, n.1, 2- 18, 1998. 
STEVENSON, W. J. Estatística Aplicada à Administração. São Paulo: Harper \& Row do Brasil, 1981.

STEWART, T. A. The wealth of knowledge: intellectual capital and the twenty-first century organization. New York: Doubleday, 2001.

STAHL, F.; HEITMANN, M.; LEHMANN, D. R.; NESLIN, Scott. The impact of brand equity on customer acquisition, retention, and profit margin. Journal of Marketing, v. 76, n. 4, p. 4463, 2012.

UPTON, W. S. Business and Financial Reporting, Challenges from the New Economy. Financial Accounting Series - Special Report. USA: FASB, 2001.

VILLALONGA, B. Intangible resources, Tobin's q, and sustainability of performance differences. Journal of Economic Behavior \& Organization, v. 54, p.205-230, 2004.

WAGNER, M. B.; MOTTA, V. T.; DORNELLES, C. SPSS Passo a Passo: Statiscal package for the social sciences - Caxias do Sul: Educs, 2004. 